\title{
NORMAS ESPECIALES EN EL PROCEDIMIENTO DE HUELGA (PRIMERA PARTE)*
}

\author{
SPECIAL RULES ON THE PROCEDURE TO STRIKE \\ NORMES SPÉCIFIQUES DANS LA PROCÉDURE \\ DE RECOURS À LA GRÈVE
}

Carlos Alberto PUIG HERNÁNDEZ ${ }^{* *}$

RESUMEN: En nuestra primera Ley Federal del Trabajo, en vigor a partir del 28 de agosto de 1931, no existió un procedimiento de huelga, sino normas sustantivas que regulaban el ejercicio del derecho de huelga por parte de los trabajadores; en la segunda versión de nuestra Ley Federal del Trabajo, vigente del 1o. de mayo de 1970 al 30 de abril de 1980, el legislador federal mexicano mantuvo el esquema, sin embargo incorporó normas especiales en la materia, las cuales se conservaron en la reforma procesal del 1o. de mayo de 1980, pero se creó un procedimiento de huelga, el cual no sufrió modificación alguna con motivo de la reforma publicada en el Diario Oficial de la Federación del 30 de noviembre del 2012; por lo tanto, las normas generales previstas en el derecho procesal del trabajo respecto del funcionamiento del Pleno y de las Juntas Especiales, la falta de personalidad, la incompetencia, los impedimentos y excusas, los términos procesales y las notificaciones, así como los incidentes, presentan particularidades en el procedimiento de huelga que las distinguen frente a los demás procedimientos laborales, cuyas características y aplicación constituyen el estudio objeto del presente artículo.

Palabras clave: derecho de huelga, procedimiento de huelga y normas especiales del procedimiento de huelga.

Recibido el 3 de marzo de 2016 y aceptado para su publicación el 14 de septiembre de

** Magistrado presidente del Tribunal Electoral del Estado de Morelos. 
ABSTRACT: In our first Federal Labor Law, in force since August 28, 1931, there wasn't an strike procedure, but there were substantive rules governing the exercise of the right to strike by workers; in the second version of our Federal Labor Law, effective from 1 May 1970 to 30 April 1980, the Mexican federal legislator maintained the scheme, however incorporated special rules on the matter, which were preserved in the Reformation procedure on 1 May 1980, but a process of strike was created, which did not suffer any modification with the Reform published in the "Official Gazette" of the Federation of November 30, 2012; therefore, the general rules provided in the Procedural Labor Law regarding the functioning of the plenary and the Special Boards, lack of personality, incompetence, impediments and excuses, procedural terms and notifications as well as incidents occur particularities in the strike procedure that distinguish them against other labor procedures, the characteristics and application are the study object of this article.

Keywords: right to strike, strike procedure and special rules of procedure strike.

RÉSUMÉ: Dans notre première loi fédérale sur le travail, en vigueur depuis le 28 Août 1931, il n’y avait pas de procédure de grève, mais les règles de fond régissant l'exercice du droit de grève des travailleurs; dans la deuxième version de notre loi fédérale sur le travail, à compter du 1er mai 1970 au 30 Avril 1980, le législateur fédéral mexicain a maintenu le régime, cependant incorporé des règles particulières en la matière, qui ont été conservés dans la Réforme procédure le 1er mai 1980, mais un processus de grèves, qui n'a pas subi de modification à l'occasion de la Réforme publiée dans le "Journal officiel" de la Fédération du 30 Novembre, 2012 a été mis; par conséquent, les règles générales prévues dans la loi sur le travail de procédure concernant le fonctionnement de la plénière et les commissions spéciales, le manque de personnalité, l'incompétence, les obstacles et les excuses, les termes et les notifications de procédure ainsi que des incidents se produisent particularités de la procédure de grève qui les distinguent par rapport aux autres procédures de travail, les caractéristiques et l'application font l'objet d'étude de cet article.

Mots-clés: droit de grève, la procédure de grève et des règles spéciales de grève de la procédure. 
Esta revista forma parte del acervo de la Biblioteca Jurídica Virtual del Instituto de Investigaciones Jurídicas de la UNAM

SumARIO: I. Nociones preliminares. II. Funcionamiento del Pleno. III. Funcionamiento de las Juntas Especiales. IV. Intervención personal del presidente. V. Notificaciones y términos procesales. VI. No denunciabilidad de los miembros de la Junta de Conciliación y Arbitraje.

In memoriam: Néstor de Buen Lozano*

\section{NOCIONES PRELIMINARES}

$\mathrm{E}$ 1 vigente artículo 928 de la Ley Federal del Trabajo (LFT) procede de la reforma procesal de $1980,{ }^{1}$ con el mismo número, en tanto que, en la LFT de 1970, ${ }^{2}$ correspondió al numeral 458 y no existió en la LFT de 1931; consecuentemente, las normas especiales que analizamos en este ensayo fueron creadas en nuestro segundo ordenamiento laboral federal, cuyo contenido legislativo recogió algunos criterios de autoridades de amparo; el texto primigenio comparado con el tenor actual del precepto presenta las siguientes reformas y adiciones:

1) Fracción I, inciso d): se adicionó el caso del artículo 923 (denegación del trámite al escrito de emplazamiento de huelga);

2) Fracción III: se adicionó la oración: "La Junta tendrá guardias permanentes para tal efecto";

3) Fracción IV: se sustituyó el adjetivo "denunciables" por el de "recusables" y se agregó la frase "en los términos del artículo 710 de esta Ley”; y

4) Fracción V, párrafo segundo: se adicionó la oración: "lo que se hará saber a las partes en la resolución de incompetencia".

* El 25 de abril de 2016 me enteré del lamentable fallecimiento del querido maestro emérito de la Universidad Nacional Autónoma de México, doctor en derecho, Néstor de Buen Lozano, prolífico autor y reconocido especialista en derecho del trabajo, tanto en México como en el mundo; para mí fue un modelo de investigador jurídico y ser humano que mucho extrañaré, pero del cual trataré de seguir su ejemplo, convencido de que sus logros personales y profesionales son inconmensurables.

1 DOF del 4 de enero de 1980.

2 DOF, sección segunda, del 1o. de abril de 1970. 
El texto actual del párrafo introductorio del artículo 928 dispone que: "En los procedimientos a que se refiere este capítulo se observarán las normas siguientes"; el capítulo al que se alude es el XX, ${ }^{3}$ el cual lleva por nombre "Procedimiento de huelga", por lo que se advierte una falta de sistematización entre el contenido del párrafo citado y la denominación del capítulo, pues aquél hace referencia a varios procedimientos al utilizar el nombre en plural, y éste a uno sólo al emplear el número gramatical singular; el artículo $920^{4}$ concuerda con el nombre del capítulo, pues en su párrafo preliminar indica que: "El procedimiento se iniciará mediante la presentación del pliego de peticiones", pero de los artículos 930, 933 y 937, párrafo segundo, se desprenden — respectivamente— los siguientes procedimientos:

a) De declaración de inexistencia de la huelga;

b) De calificación de ilicitud de la huelga; y

c) De imputabilidad de la huelga.

El procedimiento de imputabilidad de la huelga, mencionado en el inciso c), al que implícitamente hace referencia el artículo 937, párrafo segundo, al disponer que si la Junta declara en el laudo que los motivos de la huelga son imputables al patrón, condenará a éste a la satisfacción de las peticiones de los trabajadores en cuanto sean procedentes, y al pago de los salarios correspondientes a los días que hubiese durado la huelga, pero que en ningún caso será condenado el patrón al pago de los salarios de los trabajadores que hubiesen declarado una huelga en los términos del artículo 450, fracción VI, ${ }^{5}$ de esta Ley, no se trata, en estricto sentido procesal, de un juicio especial de huelga, ya que, como lo especifica el párrafo primero del mismo numeral 937, si el conflicto motivo de la huelga se somete por los trabajadores a la decisión de la Junta, se seguirá el procedimiento ordinario o el procedimiento para conflictos colectivos de naturaleza económica, según el caso.

Consecuentemente, dependerá de la naturaleza del conflicto que haya dado origen a la huelga, esto es, colectivo de naturaleza jurídica o de orden económico, para que se aplique uno u otro procedimiento, a saber, el que

\footnotetext{
3 Que forma parte del título decimocuarto denominado "Derecho Procesal del Trabajo".

4 Cuando solamente se cite el número de un artículo se debe entender referido a la LFT.

5 Huelga de apoyo o por solidaridad.
} 
corresponde a las controversias colectivas jurídicas, previsto en el capítulo XVII "Procedimiento Ordinario ante las Juntas de Conciliación y Arbitraje" (artículos 870 a 891), o el que atañe a las cuestiones de contenido económico, regulado en el capítulo XIX "Procedimiento de los Conflictos Colectivos de Naturaleza Económica” (artículos 900 a 919), ${ }^{6}$ dicotomía determinada por la existencia de una norma legal o contractual (contrato colectivo de trabajo o contrato-ley) que sirva de fundamento para resolver el conflicto, en el primer caso, y la inexistencia de una norma de derecho que permita decidir la controversia, por lo que la Junta de Conciliación y Arbitraje (JCA) tiene que resolver teniendo en cuenta consideraciones de carácter económico, en el segundo supuesto.

Por lo tanto, no se trata de aplicar en ambos casos, un procedimiento especial relativo a la huelga, sino de alguno de los dos que resultan genéricos para tramitar los conflictos colectivos de naturaleza jurídica o de orden económico, según corresponda, en virtud de lo cual, podemos excluirlo de los procedimientos de huelga y, en consecuencia, sólo nos quedarían como tales los que corresponden a la declaración de inexistencia de la huelga y a la calificación de ilicitud de la huelga.

En principio, debe destacarse que, como lo expuse en obras anteriores, ${ }^{7}$ discrepamos de la creación del procedimiento de huelga, por parte del legislador federal autor de la reforma laboral de 1980, al reubicar "varios artículos que regulan el procedimiento de huelga y que actualmente se encuentran incluidos en la parte substantiva de la Ley", ${ }^{8}$ pues no se tomaron en cuenta las características de la huelga que se derivan de su reconocimiento constitucional, las cuales deben determinar su naturaleza especial en la legislación mexicana, como son su ejercicio directo y su calidad instrumental, pues se trata de la facultad reconocida a favor de los trabajadores cuya finalidad es presionar al empleador para que acepte las peticiones contenidas en el pliego

6 Ambos procedimientos forman parte del título decimocuarto "Derecho Procesal del Trabajo" de la LFT.

7 Teoría y práctica de la buelga en México, México, Porrúa, 1989, pp. 245-260, y Temas sobre el procedimiento de buelga, México, Porrúa, 2007, pp. 5 y 6.

8 Iniciativa de Decreto sobre la Ley Federal del Trabajo, de fecha 18 de diciembre de 1979, consultada en Poder Judicial de la Federación, Historia legislativa y parlamentaria VI. Laboral y agrario, México, Suprema Corte de Justicia de la Nación, Dirección General de Documentación y Análisis, disco compacto, 2000. 
de peticiones, y no demandar al patrón ante el tribunal laboral para que lo condene al pago de las prestaciones reclamadas, por lo cual, no podemos separar a la huelga en un aspecto sustantivo y otro adjetivo, ya que sólo se instrumenta referida a contenidos sustantivos, pero no se puede ejercer en forma separada, dado que no es posible desligar el ejercicio del derecho de huelga de su finalidad.

Sin embargo, toda vez que la LFT reconoce el procedimiento de huelga, llevaremos a cabo el análisis jurídico correspondiente en los términos de la legislación vigente, esto es, en el campo del derecho positivo y, al respecto, debemos recordar que en su texto original, la LFT de 1931,9 reconoció el ejercicio del derecho de huelga en su modalidad constitucional ortodoxa, a la cual hemos denominado inter partes,,$^{10}$ toda vez que la entrega del pliego de peticiones al patrón se efectuaba directamente por los trabajadores, esto es, no se presentaba ante la JCA competente, y era su presidente quien lo entregaba al emplazado, y las pláticas se realizaban entre los dos sujetos de la relación colectiva del trabajo, sin la intervención de alguna autoridad laboral; en caso de que la huelga hubiera estallado porque los trabajadores y el patrón no llegaran a algún acuerdo conciliatorio que pusiera fin al conflicto laboral, ya intervenía la JCA para resolver si la huelga había sido ilícita (artículo 268) o se había declarado sin cumplir los requisitos legales (artículos 264, fracción II; 265, fracciones I y III; y 269, párrafo inicial), ambos temas que el legislador de 1931 denominó como “declaratorias” (artículo 270).

El 10 de abril de $1941^{11}$ se modificaron las normas aplicables al ejercicio del derecho de huelga previstas en la LFT de 1931, con lo cual inició la etapa que denominamos ejercicio triangular del derecho de buelga, ${ }^{12}$ toda vez que el pliego de peticiones debe ser presentado ante la JCA, acompañado de una copia que el presidente de dicha Junta debe hacer llegar al patrón el mismo día de su recepción, y la JCA tenía que ejercer su función conciliatoria para intentar avenir a las partes, pero si los obreros no comparecían a la conciliación, no

9 Cfr. DOF del 28 de agosto de 1931. Nota: el título quinto de dicha ley, integrado por los artículos 258 a 283, no reconoció ningún procedimiento de huelga, pues sólo se denominó "De las coaliciones, huelgas y paros".

10 Cfr. mi obra anterior La buelga en los servicios públicos de México, México, Porrúa, 2011, pp. 31-66.

11 Cfr. DOF del 10 de abril de 1941.

12 Cfr. Puig Hernández, Carlos Alberto, La buelga en los servicios..., cit., pp. 66-88. 
corría el plazo que se hubiere señalado en el aviso para la iniciación de la huelga, aunque no se modificó el artículo 270 que señaló a la ilicitud y a la inexistencia como "declaratorias", no como procedimientos.

Fue la LFT de $1970^{13}$ la que agrupó en su título octavo, "Huelgas", las normas sobre el ejercicio de este derecho colectivo, ${ }^{14}$ subdividido en dos capítulos: I. Disposiciones generales (artículos 440 a 449) y II. Objetivos y procedimientos de huelga (artículos 450 a 471); como puede advertirse, fue el legislador federal de 1970 quien incorporó el concepto de "procedimientos" en esta materia y lo desarrolló en los artículos 458 ("En los procedimientos a que se refiere este capítulo"), 461 ("En el procedimiento de declaración de inexistencia de la huelga") y 464 ("En el procedimiento de declaración de ilicitud de la huelga"), abandonando la denominación de "declaratorias".

El esquema conceptual referido en el párrafo inmediato anterior fue reproducido en la reforma procesal de 1980, ya que — como vimos con anterioridad - el legislador federal sólo reubicó varios artículos que regulaban el procedimiento de huelga y que se encontraban incluidos en la, supuesta, parte sustantiva de la ley; los vigentes numerales 920 a 937 — que desarrollan el procedimiento citado - no fueron modificados con motivo de la reforma laboral del 2012, ${ }^{15}$ por lo que conservan el tenor aprobado por el legislador federal de 1980.

Como hicimos notar al principio de este artículo, al contrastar el nombre del capítulo XX y el contenido del vigente artículo 920 frente al tenor de los preceptos 928, 930 y 933, obtenemos como conclusión una evidente contradicción, que revela una falta de técnica jurídica por parte del Poder Legislativo federal, pues tanto el capítulo como el numeral citados hacen referencia a un sólo procedimiento de huelga, en tanto que los tres artículos restantes aluden a procedimientos en plural, lo cual hace necesario aplicar una interpretación

13 Cfr. página disponible en http:// wmm.dof.gob.mx/nota_to_imagen_fs.php?cod_diario=201227 Spagina $=40 \&$ seccion $=2$ (consultada el 5 de diciembre de 2015; véase DOF del 1o. de abril de 1970).

14 Separándolas de las "Relaciones colectivas de trabajo" incluidas en el título séptimo, integrado por los capítulos I. Coaliciones, II. Sindicatos, federaciones y confederaciones, III. Contrato colectivo de trabajo, IV. Contrato-ley, V. Reglamento interior de trabajo, VI. Modificación colectiva de las condiciones de trabajo, VII. Suspensión colectiva de las relaciones de trabajo y VIII. Terminación colectiva de las relaciones de trabajo.

15 Cfr. "Decreto por el que se reforman, adicionan y derogan diversas disposiciones de la Ley Federal del Trabajo", DOF del 30 de noviembre de 2012. 
sistemática y funcional que nos permita concluir que en el procedimiento general de huelga, y de acuerdo con el texto aprobado por el legislador, existen dos procedimientos particulares que norman la declaración de inexistencia de la huelga y la calificación de su ilicitud, aunque debe destacarse que, en estricto sentido procesal, podemos considerar que los dos procedimientos a los que se alude tienen la naturaleza jurídica adjetiva de un incidente y no son propiamente procedimientos independientes.

Sostenemos que el par de procedimientos en comento poseen una naturaleza incidental, ya que, como lo define el maestro Eduardo Pallares: "Los incidentes son las cuestiones que surgen durante el juicio y que tienen relación con la cuestión litigiosa principal o con el procedimiento". ${ }^{16}$ Es importante destacar que —en esta definición — el jurista citado hace referencia al juicio y al procedimiento, distinción que es significativa para precisar las características de la declaración de inexistencia de la huelga y la calificación de su ilicitud como incidentes, pues esta connotación aplica por cuanto al procedimiento, no así respecto de la cuestión litigiosa principal, toda vez que el procedimiento de huelga no tiene un carácter jurisdiccional, ya que en él no se resuelve el fondo del conflicto laboral que se hubiere generado entre los trabajadores y el empleador.

Esta diferencia entre juicio y procedimiento es fácil de advertir en materia de huelga, con base en el texto de la tesis aislada sustentada por la desaparecida Cuarta Sala de la Suprema Corte de Justicia de la Nación (SCJN), cuyo rubro es "HuELGa, RESOLUCIONES DURANTE EL PROCEDIMIENTO DE", en la cual se menciona que: "las resoluciones tomadas por una Junta durante el procedimiento de huelga, son completamente ajenas al juicio laboral que se plantea con motivo del sometimiento que los trabajadores hacen ante la misma para que decida el conflicto que la motivó". ${ }^{17}$

16 Citado por Saucedo López, Antonio, "Los incidentes en el amparo"; disponible en bttp:// mwn.juridicas.unam.mx/publica/librev/ rev/jurid/cont/18/pr/pr7.pdf (consultada el 6 de diciembre de 2015).

17 Tesis aislada, Semanario Judicial de la Federación, Séptima Época, vol. 199-204, p. 21. Nota primera del autor: cuatro amparos directos fueron resueltos con base en el mismo criterio. Nota segunda del autor: de conformidad con lo dispuesto en el artículo transitorio séptimo del decreto publicado el dos de abril de dos mil trece, en el DOF, por el que se expidió la Ley de Amparo, Reglamentaria de los Artículos 103 y 107 de la Constitución Política de los Estados Unidos Mexicanos, que abrogó la publicada en el medio citado, el 10 de enero de 1936: "Para la integración de la jurisprudencia por reiteración de criterios a que se refiere la presente Ley no 
Similar criterio sostuvo el Primer Tribunal Colegiado en Materia de Trabajo del Primer Circuito al resolver — con fecha 27 de abril de 1995 y por unanimidad de votos - el amparo directo 3741/95 del quejoso Sindicato Nacional de Trabajadores Permisionarios del Autotransporte, Similares y Conexos de la República Mexicana, en la tesis aislada de rubro "HuELGA. LA RESOLUCIÓN QUE NIEGA DAR TRÁMITE AL EMPLAZAMIENTO NO ES IMPUGNABLE EN AMPARO DIRECTO”, en la que se señala que:

el procedimiento de huelga tiene por objeto garantizar la suspensión de labores cuando se han cumplido las formalidades previstas por la propia ley, sin que exista pronunciamiento alguno respecto al fondo del conflicto $[\ldots]$ en el procedimiento de huelga [...] ni siquiera se prejuzga sobre una solución adecuada, sino que su finalidad es tutelar jurídicamente el paro de actividades porque se han observado los requisitos de fondo y forma estipulados por la ley. ${ }^{18}$

En el mismo sentido, el Sexto Tribunal Colegiado en Materia de Trabajo del Primer Circuito resolvió —el 7 de noviembre de 2001 y por unanimidad de votos- el amparo directo 14736/2001, promovido por la Asociación Nacional de Actores, conforme a la tesis aislada de rubro "HUELGA, PROCEDIMIENTO DE. LAS RESOLUCIONES EMITIDAS EN ÉL, SON IMPUGNABLES EN AMPARO INDIRECTO", en la cual expuso que:

el procedimiento de huelga previsto en el capítulo XX, título decimocuarto, de la Ley Federal del Trabajo, tiene por objeto garantizar la suspensión de labores cuando se han cumplido las formalidades previstas por la propia ley, sin que exista pronunciamiento alguno respecto al fondo del conflicto; en tanto que el juicio es un procedimiento contencioso que concluye con

se tomarán en cuenta las tesis aprobadas en los asuntos resueltos conforme a la ley anterior". Sin embargo, los criterios de interpretación contenidos en tesis aisladas —anteriores a la vigencia de la nueva Ley de Amparo- pueden ser tomados en consideración al hacer el estudio jurídico de la cuestión planteada y aplicarlos al caso de que se trate.

18 Tesis I.1o.T.18 L, Semanario Judicial de la Federación y su Gaceta, Novena Época, t. II, octubre de 1995, p. 555. Nota: el criterio contenido en esta tesis contendió en la contradicción de tesis 57/95, resuelta por la Segunda Sala, de la que derivó la tesis 2a./J. 34/96, Semanario Judicial de la Federación y su Gaceta, Novena Época, t. IV, julio de 1996, p. 193, con el rubro: HuELGA, EMPLAZAMIENTO A. EL ACUERDO QUE ORDENA NO DARLE TRÁMITE Y ARCHIVAR EL EXPEDIENTE, ES RECLAMABLE EN AMPARO INDIRECTO. 
la sentencia, es decir, se trata de un actuar jurisdiccional que tiene como fin resolver un conflicto de intereses. ${ }^{19}$

Consecuentemente, el procedimiento de huelga, previsto en la vigente LFT, que no tiene carácter jurisdiccional, ${ }^{20}$ ya que no se relaciona con el fondo del conflicto laboral, podemos denominarlo como general para distinguirlo de los dos procedimientos particulares que regulan la declaración de inexistencia de la huelga y la calificación de su ilicitud, los cuales, en su exacta acepción procesal, poseen la naturaleza jurídica adjetiva de un incidente y no son exactamente procedimientos independientes, pues guardan relación directa con el procedimiento que inicia, como lo dispone el artículo 920, con la presentación del pliego de peticiones, por parte del sindicato o coalición emplazante.

En tal orden de ideas, podemos referir, en los términos que a continuación se exponen, los cuatro elementos que nos permiten distinguir entre el fondo del conflicto, materia de la huelga —el cual se resuelve por medio de los procedimientos ordinario o para conflictos colectivos de naturaleza económica, en el que se determina la imputabilidad a cargo del patrón o de los trabajadores-, y la declaración de inexistencia de la huelga, así como la calificación de su ilicitud, las cuales poseen la naturaleza jurídica procesal de incidentes, pero al no ser el de huelga un procedimiento jurisdiccional, las podemos denominar — como lo hizo el legislador de la LFT de 1931 — como declaratorias, las que se tramitan, en caso de que se planteen, de conformidad con lo dispuesto en los artículos 929 a 934.

\section{Por la materia a la que se refieren}

a) Fondo del conflicto materia de la huelga: constituye la cuestión principal del asunto, de acuerdo con el o los objetos de huelga expresados concretamente en el pliego de peticiones. ${ }^{21}$

19 Tesis I.6o.T.118 L, Semanario Judicial de la Federación y su Gaceta, Novena Época, t. XV, marzo de 2002, p. 1354. Véase Semanario Judicial de la Federación, Octava Época, t. XIII, febrero de 1994, p. 331; y tesis I.4o.T.151 L, de rubro: HuELGA, PROCEDIMIENTO DE. LA RESOLUCIÓN CON QUE CONCLUYE ES UN ACTO IMPUGNABLE EN AMPARO INDIRECTO.

20 El Pleno de la SCJN resolvió el 24 de septiembre de 1957 la Competencia 47/57, en la que sostuvo: "Hasta antes de que estalle la huelga, la intervención de las autoridades laborales [...] no tiene carácter jurisdiccional", Informe 1957, p. 170.

21 “Artículo 450. La huelga deberá tener por objeto: I. Conseguir el equilibrio entre los 
b) Declaración de inexistencia de la huelga: se relaciona con el cumplimiento de los requisitos (de fondo, mayoría y forma), ${ }^{22}$ por parte de los trabajadores, que garantizan la suspensión de las labores.

c) Calificación de ilicitud de la huelga: atañe al desarrollo pacífico de la huelga y que no la lleven a cabo los trabajadores pertenecientes a establecimientos o servicios que dependan del gobierno. ${ }^{23}$

\section{Por las consecuencias jurídicas que origina su resolución}

a) Fondo del conflicto materia de la huelga: se decide la cuestión principal del asunto, esto es, si la huelga es justificada porque sus motivos sean imputables al patrón, ${ }^{24} \mathrm{O}$-mediante una interpretación contrario sensu— si resulta injustificada porque sus motivos sean atribuibles a los trabajadores.

b) Declaración de inexistencia de la huelga: resuelve si se cumplieron o no los requisitos de mayoría, fondo y forma. ${ }^{25}$

diversos factores de la producción, armonizando los derechos del trabajo con los del capital; II. Obtener del patrón o patrones la celebración del contrato colectivo de trabajo y exigir su revisión al terminar el período de su vigencia, de conformidad con lo dispuesto en el capítulo III del título séptimo; III. Obtener de los patrones la celebración del contrato-ley y exigir su revisión al terminar el período de su vigencia, de conformidad con lo dispuesto en el capítulo IV del título séptimo; IV. Exigir el cumplimiento del contrato colectivo de trabajo o del contratoley en las empresas o establecimientos en que hubiese sido violado; V. Exigir el cumplimiento de las disposiciones legales sobre participación de utilidades; VI. Apoyar una huelga que tenga por objeto alguno de los enumerados en las fracciones anteriores; y VII. Exigir la revisión de los salarios contractuales a que se refieren los artículos 399 bis y 419 bis".

22 "Artículo 451. Para suspender los trabajos se requiere: I. Que la huelga tenga por objeto alguno o algunos de los que señala el artículo anterior; II. Que la suspensión se realice por la mayoría de los trabajadores de la empresa o establecimiento. La determinación de la mayoría a que se refiere esta fracción, sólo podrá promoverse como causa para solicitar la declaración de inexistencia de la huelga, de conformidad con lo dispuesto en el artículo 460, y en ningún caso como cuestión previa a la suspensión de los trabajos; y III. Que se cumplan previamente los requisitos señalados en el artículo siguiente". Nota: la fracción III erróneamente remite al artículo 452 que está derogado, por lo que el correcto es el artículo 920.

23 "Artículo 445. La huelga es ilícita: I. Cuando la mayoría de los huelguistas ejecuten actos violentos contra las personas o las propiedades; y II. En caso de guerra, cuando los trabajadores pertenezcan a establecimientos o servicios que dependan del gobierno".

24 "Artículo 446. Huelga justificada es aquella cuyos motivos son imputables al patrón".

25 "Artículo 459. La huelga es legalmente inexistente si: I. La suspensión del trabajo se realiza por un número de trabajadores menor al fijado en el artículo 451, fracción II; II. No 
c) Calificación de ilicitud de la huelga: determina si la mayoría de los huelguistas ejecutó actos violentos contra las personas o las propiedades, o se efectuó en caso de guerra, y los trabajadores pertenecen a establecimientos o servicios que dependen del gobierno.

\section{Por el momento en que se resuelven}

a) Fondo del conflicto materia de la huelga: al concluir el trámite del procedimiento ordinario o del procedimiento de los conflictos colectivos de naturaleza económica.

b) Declaración de inexistencia de la huelga: una vez desahogado el trámite previsto en el artículo 930, y cuando se haga valer — como causa de inexistencia de la huelga - que fue la minoría de trabajadores la que suspendió el trabajo, practicado el recuento respectivo, como lo dispone el artículo 931.

c) Calificación de ilicitud de la huelga: al concluir el trámite a que se refiere el artículo 933, el cual remite al 930 y, en su caso, al 931.

\section{Por la clase de juicio de amparo procedente}

a) Fondo del conflicto materia de la huelga: juicio de amparo directo o uni instancial.

b) Declaración de inexistencia de la huelga: juicio de amparo indirecto o bi instancial.

c) Calificación de ilicitud de la huelga: juicio de amparo indirecto o bi instancial.

Por lo expuesto con anterioridad, opinamos que el texto del artículo 928 debe ser reformado para acotar el vocablo "procedimientos", que se utiliza en el párrafo inicial, a su número singular y, por ende, dispondría: "En el procedimiento a que se refiere este capítulo”, con lo cual, su tenor resultaría acorde con el nombre del capítulo XX (Procedimiento de huelga) y con el contenido

ha tenido por objeto alguno de los establecidos en el artículo 450; y III. No se cumplieron los requisitos señalados en el artículo 452. No podrá declararse la inexistencia de una huelga por causas distintas a las señaladas en las fracciones anteriores". 
del artículo 920, en su párrafo introductorio ("El procedimiento de huelga se iniciará..."); de igual manera, el texto de los numerales 930 y 933 debe ser reformado para suprimir la idea de que la declaración de inexistencia de la huelga y la calificación de su ilicitud son procedimientos particulares, para lo cual habría dos posibilidades:

1) Suprimir la palabra procedimiento en ambos preceptos para que queden como sigue:

930. En la declaración de inexistencia de la huelga, se observarán las normas siguientes:

$[\ldots]$

933. En la calificación de ilicitud de la huelga, se observarán las normas contenidas en el artículo 930 de esta Ley.

2) Agregar el concepto procesal específico de "incidente", de la siguiente forma:

930. En el incidente de inexistencia de la huelga, se observarán las normas siguientes:

$[\ldots]$

933. En el incidente de calificación de ilicitud de la huelga, se observarán las normas contenidas en el artículo 930 de esta Ley.

En la medida que nosotros consideramos que el ejercicio del derecho de huelga no es un procedimiento jurisdiccional, opinamos que resulta más adecuada la primera de las dos posibilidades planteadas, esto es, eliminar la palabra procedimiento en los numerales 930 y 933, para que directamente se haga referencia a "la declaración de inexistencia de la huelga" y a "la calificación de ilicitud de la huelga", es decir, volver al esquema original de la LFT de 1931, y considerar implícitamente a ambos temas como "declaratorias", sin dejar de reconocer que, en un esquema propio de derecho procesal, el concepto de incidente resultaría aplicable a ambos casos; sin embargo, debemos recordar que la fracción IV del artículo 928 dispone que — en materia de huelga— no se admitirán más incidentes que el de falta de personalidad, en virtud de lo cual, nos inclinamos por nuestro planteamiento inicial (suprimir el vocablo 
"procedimiento" en los dos preceptos citados) o, en caso contrario, agregar como salvedad al incidente de falta de personalidad, los de inexistencia de la huelga y el de calificación de ilicitud de la huelga.

Carlos de Buen Unna, respecto del artículo 928 que analizamos, comenta que: "Destaca la celeridad que se trata de lograr en el procedimiento de huelga. Como una excepción a lo dispuesto en el artículo 762, la incompetencia no se tramita por vía incidental. De hecho, el único incidente posible es el de falta de personalidad y debe resolverse de inmediato (artículo 927, fracción I)". ${ }^{26}$

Por su parte, Néstor de Buen expone, sobre el texto del referido numeral 928: "Un hermoso cuadro de reglas rígidas donde la invocada flexibilización patronal tan de moda, debía extenderse al procedimiento de huelga, al que no le hace falta la intervención de las juntas de conciliación y arbitraje". ${ }^{27}$

\section{FunCionamiento Del Pleno}

En materia de huelga, el artículo 928, fracción I, dispone que para el funcionamiento del Pleno y de las Juntas Especiales se observará lo dispuesto en el artículo 620; en su fracción I, tal precepto indica que: "En el Pleno se requiere la presencia del presidente de la Junta y de la mayoría de los representantes de los trabajadores y de los patrones, respectivamente. En caso de empate, el presidente tendrá voto de calidad".

Conviene recordar que el Pleno de la $\mathrm{JCA}^{28}$ debe conocer y resolver los conflictos de trabajo cuando afecten a la totalidad de las ramas de la industria y de las actividades representadas en la propia Junta, en términos de lo dispuesto en el artículo 614, fracción II; por lo tanto, en el ámbito federal,

26 Buen Unna, Carlos de, Ley Federal del Trabajo. Análisis y comentarios, 6a. ed., México, Themis, 2000, pp. 927-928 y 928-930. El artículo 762 que cita el comentarista, dispone: "Se tramitarán como incidentes de previo y especial pronunciamiento las siguientes cuestiones: $\mathrm{I}$. Nulidad; II. Competencia; III. Personalidad; IV. Acumulación; y V. Excusas".

27 Buen L., Néstor de, Compilación de normas laborales (comentadas), colaboración de Claudia de Buen Unna, México, Porrúa, 2002, t. II, pp. 302 y 303.

28 Los comentarios aplican tanto en la competencia federal como en la local, ya que la Junta Federal de Conciliación y Arbitraje se regula por las disposiciones contenidas en el capítulo XII (artículos 604 a 620) del título decimoprimero Autoridades del trabajo y servicios sociales, y las Juntas Locales de Conciliación y Arbitraje se rigen por las mismas disposiciones con las normas especiales previstas en el capítulo XIII del mismo título. 
cuando el asunto planteado involucre a las ramas industriales y actividades que competen a las dieciséis Juntas Especiales de la Federal de Conciliación y Arbitraje establecidas en la capital de la República (hoy Ciudad de México), debe atender la controversia laboral el presidente titular de dicha Junta con todos los representantes del trabajo y del capital de las citadas dieciséis Juntas Especiales, ${ }^{29}$ ubicadas en la Ciudad de México.

En el Pleno, no tienen intervención alguna ni los presidentes ni los representantes del trabajo y del capital de las Juntas Especiales establecidas fuera de la capital de la República, a las que se refiere el artículo 606, párrafo tercero, a las cuales sólo corresponde el conocimiento y resolución de los conflictos laborales en las ramas de la industria y actividades de la competencia federal, comprendidas en la jurisdicción territorial que se les asigne, con excepción de los conflictos colectivos, pero es opcional para el trabajador, cuando así convenga a sus intereses en asuntos individuales, concurrir directamente a la Junta competente de la Ciudad de México.

Es evidente que: a) La Junta Especial de la Federal de Conciliación y Arbitraje establecida en la Ciudad de México que tramite un procedimiento de huelga, puede solicitar el apoyo de una Junta Especial federal foránea para la práctica de alguna diligencia, en términos de lo dispuesto en el artículo 688 (que dispone que las Juntas se auxiliarán entre sí en el ejercicio de sus funciones) y en los preceptos relativos al desahogo de los exhortos (artículos $753,757,758,759$ y 760); y b) Cuando la empresa o establecimiento estén ubicados en lugar distinto al en que resida la Junta competente, el sindicato o coalición emplazante podrá presentar el pliego de peticiones a la autoridad de trabajo más próxima o a la autoridad política de mayor jerarquía del lugar de ubicación de la empresa o establecimiento, la que deberá remitir el expediente dentro de las veinticuatro horas siguientes a la JCA, y avisará telegráfica o telefónicamente ${ }^{30}$ al presidente de la Junta, de conformidad con lo dispuesto en el artículo 920, fracción II.

29 Los presidentes de las Juntas Especiales no tienen intervención legal en los conflictos colectivos, en términos de lo dispuesto en el artículo 609, fracción I.

30 Bien pudo aprovechar la oportunidad, el legislador federal de la reforma laboral de 2012, para actualizar esta disposición, y sustituir el telégrafo y el teléfono por la notificación informática. 
Sobre el artículo 606 citado, resulta pertinente mencionar que Juan B. Climént Beltrán nos refiere el origen y las razones que —en su opinión- motivaron la creación de las Juntas Especiales federales foráneas, las cuales sólo conocen de los conflictos individuales no así de los colectivos, por lo que no intervienen en el procedimiento de huelga, así como la excepción relacionada con los trabajadores de las universidades e instituciones de educación superior autónomas por ley. ${ }^{31}$

En relación con la creación de las citadas Juntas Especiales foráneas que, en opinión de Climént Beltrán, tuvo por objeto que los trabajadores y patrones pudieran ventilar sus litigios y asuntos laborales en lugares cercanos a los centros de trabajo, evitándoles el tener que trasladarse a la Ciudad de México desde lugares distintos, es importante recordar que —en materia de huelga - el legislador federal, treinta y cinco años antes, procuró facilitar a los trabajadores la entrega del pliego de peticiones, cuando la empresa o establecimiento estuvieran ubicados en lugar distinto al de ubicación de la JCA, mediante la presentación ante la autoridad del trabajo más próxima o a la autoridad política de mayor jerarquía del lugar de localización de la empresa o establecimiento, al través de la adición del párrafo segundo de la fracción II del artículo 265 de la LFT de 1931,32 la cual fue una propuesta de la Comisión de Diputados que dictaminó el proyecto de reformas correspondiente, planteada en los siguientes términos:

La Comisión estima que debe completarse la parte final de la fracción II del artículo 265, en el sentido de dar posibilidad a los trabajadores cuyos centros de trabajo se encuentren ubicados fuera del lugar en que resida la JCA, para que la notificación del emplazamiento de huelga se haga por conducto de la autoridad del trabajo más próxima a dicho centro o negociación; de modo que los obreros no tengan ningún obstáculo, por razones de distancia, para emplazar inmediatamente la huelga. $Y$ en caso de no poder recurrir a la autoridad de trabajo del centro de labor, entonces podrán hacerlo ante la autoridad política de mayor jerarquía del lugar. ${ }^{33}$

\footnotetext{
31 Cfr. Climént Beltrán, Juan B., Ley Federal del Trabajo. Comentarios y jurisprudencia, 23a. ed., México, Esfinge, 2002, p. 428.

32 Cfr. DOF del 10 de abril de 1941.

33 Cámara de Diputados, Congreso de los Estados Unidos Mexicanos, Diario de los Debates, 13 de marzo de 1941, p. 12.
} 
La posibilidad de presentar el pliego de peticiones con emplazamiento de huelga ante la autoridad del trabajo más próxima o la autoridad política de mayor jerarquía del lugar de localización de la empresa o establecimiento, sigue vigente en el artículo 920, fracción II.

Carlos de Buen Unna, en su comentario sobre el numeral 606, relacionado con las Juntas Especiales establecidas fuera de la capital del República, al que titula "El Pleno y las Juntas Especiales", refiere: "La JFCA es una sola en toda la República. Se limita la competencia de las Juntas Especiales a los conflictos individuales, ya que los colectivos siguen siendo tratados bajo un sistema de centralización absoluta, siendo indispensable que las partes se trasladen a la Ciudad de México, con los costos y la pérdida de tiempo que ello ocasiona". ${ }^{34}$

Por su parte, Néstor de Buen Lozano coincide con el criterio de su vástago, pues respecto del precepto aludido, comenta: "Llama la atención que la solución de los asuntos colectivos se reserve para la JFCA y no para las especiales de los Estados. En el fondo es una solución política que centraliza esos asuntos en una Junta cuya dependencia inmediata de la STPS es evidente". ${ }^{35}$

Como lo dispone el artículo 614, fracción II, el Pleno de la JCA debe conocer y resolver los conflictos de trabajo cuando afecten a la totalidad de las ramas de la industria y de las actividades representadas en la misma Junta, sin embargo, como lo hemos referido con anterioridad, el procedimiento de huelga no es un procedimiento jurisdiccional ni tiene por objeto resolver conflictos laborales, ${ }^{36}$ sino que su finalidad consiste en garantizar la suspensión de labores cuando se han cumplido las formalidades previstas por la propia ley, sin que exista pronunciamiento alguno respecto al fondo del conflicto; en consecuencia, no podemos aplicar literalmente el texto del numeral 614, fracción II, pero sí por analogía, con fundamento en el artículo 17, por tratarse de una disposición que regula un caso semejante, con cuyo fundamento podemos afirmar que, dado que las finalidades de la huelga, previstas en el

\footnotetext{
34 Buen Unna, Carlos de, Análisis de la Ley Federal del Trabajo. Comentarios y jurisprudencia, México, Themis, 2013, p. 558.

35 Buen Lozano, Néstor de, Nueva Ley Federal del Trabajo comentada, México, Porrúa, 2014, p. 256. Nota: las siglas corresponden a la Junta Federal de Conciliación y Arbitraje y a la Secretaría del Trabajo y Previsión Social, respectivamente.

36 El artículo 937, párrafo primero, dispone que si el conflicto motivo de la huelga se somete por los trabajadores a la decisión de la Junta, se seguirá el procedimiento ordinario o el procedimiento para conflictos colectivos de naturaleza económica, según el caso.
} 
artículo 450, se relacionan con - no consisten en- conflictos colectivos de naturaleza jurídica o de orden económico, el Pleno debe ser integrado por el presidente titular de la Junta.

\section{FUNCIONAMIENTO DE LAS JUNTAS ESPECIALES}

Para el funcionamiento de las Juntas Especiales — que deben integrarse con el presidente titular de la Junta y no con el de la Junta Especial, como lo ordena el artículo 609, fracción I- debe distinguirse si el procedimiento de huelga se relaciona con un conflicto colectivo de naturaleza jurídica o de carácter económico, pues el artículo 620, fracción II, dispone que, en el caso del primero:

a) Bastará la presencia de su presidente o del auxiliar, quien llevará adelante la audiencia, hasta su terminación;

b) Si están presentes uno o varios de los representantes, las resoluciones se tomarán por mayoría de votos; y

c) Si no está presente ninguno de los representantes, el presidente o el auxiliar dictará las resoluciones que procedan, salvo que se trate de las que versen sobre personalidad, competencia, aceptación de pruebas, desistimiento de la acción a que se refiere el artículo 773 y sustitución de patrón. El mismo presidente acordará que se cite a los representantes a una audiencia para la resolución de dichas cuestiones y, si ninguno concurre, dictará la resolución que proceda.

Las normas a las que se alude en los incisos a), b) y c), resultan aplicables en el procedimiento de huelga, salvo los supuestos relativos al desistimiento de la acción y a la sustitución patronal; el primero porque esa figura legal no está prevista en el procedimiento que se analiza, como lo consideró el Segundo Tribunal Colegiado en Materia de Trabajo del Tercer Circuito, al resolver —el 30 de octubre de 2009 y por unanimidad de votos- el amparo en revisión 89/2009, del quejoso Sindicato Nacional de la Industria de Trabajadores del Ramo del Autotransporte en General, San Juan Teotihuacán, con la tesis cuyo rubro indica: "Procedimiento DE HUELGa. LA CADUCIDAD A QUE SE REFIERE EL ARTícUlo 773 DE LA LEY FEDERAL DEL TRABAJO NO LE ES 
APLICABLE, EN VIRTUD DE QUE TAL CONFLICTO (REGULADO EN EL CAPÍTULO XX DE LA PROPIA LEY) NO CONTEMPLA ESA FIGURA”. 37

Tampoco resulta aplicable al procedimiento de huelga el supuesto relativo a la sustitución patronal, porque constituye un acuerdo entre el patrón sustituto y el patrón sustituido que no afecta las relaciones de trabajo, en términos de lo dispuesto en el artículo 41, en forma tal que, por ejemplo, el Tercer Tribunal Colegiado en Materia de Trabajo del Primer Circuito, al resolver —el 25 de mayo de 2004 y por mayoría de votos_ el amparo en revisión 2263/2003, promovido por el secretario general del Sindicato de Trabajadores de Casas Comerciales, Oficinas y Expendios, Similares y Conexos del Distrito Federal, consideró que, en materia de huelga, es improcedente el juicio de amparo promovido por el patrón sustituto alegando falta de emplazamiento a ese procedimiento, si consta el efectuado al patrón sustituido. ${ }^{38}$

Cuando el conflicto colectivo con el que se relacione el procedimiento de huelga sea de carácter económico, la Junta Especial, que debe integrarse con el presidente titular de la Junta y no con el de la Especial, además del presidente se requiere la presencia de uno de los representantes, por lo menos.

Por lo tanto, pareciera que sólo cuando el procedimiento de huelga se relacione con un conflicto colectivo de naturaleza jurídica, puede intervenir _ indistintamente — el presidente titular de la JCA o un auxiliar, a menos que se trate de alguno de los casos previstos en los incisos a), b), c) y d), de la fracción I, del artículo 928, en los que se requiere la participación personal del presidente, pero cuando el conflicto resulte de orden económico, es indispensable la presencia del presidente, pues la norma legal aplicable, ${ }^{39}$ no admite expresamente la intervención del auxiliar; sin embargo, debe recordarse que el numeral 610 establece la posibilidad de que el presidente de la JFCA pueda ser sustituido por auxiliares, salvo los casos previstos en las seis fracciones del mismo precepto. ${ }^{40}$

37 Tesis III.2o.T.198 L, Semanario Judicial de la Federación y su Gaceta, Novena Época, t. XXXI, febrero de 2010, p. 2897.

38 HuELGA. ES IMPROCEDENTE EL JUICIO DE AMPARO PROMOVIDO POR EL PATRÓN SUSTITUTO ALEGANDO FALTA DE EMPLAZAMIENTO A ESE PROCEDIMIENTO, SI CONSTA EL EFECTUAdo AL PATRÓn SUSTITUIDO. Tesis I.3o.T.79 L, Semanario Judicial de la Federación y su Gaceta, Novena Época, t. XX, septiembre de 2004, p. 1767.

39 Artículo 620, fracción II, inciso c).

40 "Artículo 610. Durante la tramitación de los juicios, hasta formular el proyecto de laudo 
Fernando Javier Moreno García, al exponer su concepto de "Principio circunstancial", sobre el cual comenta: "Las reglas del proceso nunca se encuentran en los códigos de procedimientos, éstos se fijan por las circunstancias", considera que son inconstitucionales las "juntas auxiliares" como la de huelgas y huelgas estalladas, entre otras; ${ }^{41}$ en nuestra opinión, no han existido ni existen juntas auxiliares sino secretarías auxiliares, respecto de las cuales no tenemos conocimiento de que, en algún caso, se hubiere cuestionado su constitucionalidad por la vía del juicio de amparo; en la actualidad, la existencia de tales órganos cuenta con fundamento legal en el artículo 605 bis, párrafo cuarto, que fue adicionado mediante el decreto publicado en el Diario Oficial de la Federación (DOF) del 30 de noviembre del 2012, el cual a la letra dice: "Los secretarios generales vigilarán la tramitación de los procedimientos de su competencia a través de los auxiliares y secretarios auxiliares que les sean adscritos, quienes, bajo su responsabilidad, deberán dictar en debido tiempo y forma, los acuerdos que procedan para asegurar la continuidad del procedimiento".

El mismo numeral 605 bis, en el párrafo quinto, dispone que, en el Reglamento Interior de la Junta Federal de Conciliación y Arbitraje se establecerán las competencias y responsabilidades respectivas; al respecto, el artículo 4o. del Reglamento de la Junta Federal de Conciliación y Arbitraje, contempla siete secretarías auxiliares, entre ellas las de "Emplazamientos a huelga" y de "Huelgas", cuyas facultades están previstas en los artículos 25 y 26, respectivamente, del mismo reglamento.42

Por otra parte, resulta una regla común al conflicto colectivo jurídico o económico con el que se vincule el procedimiento de huelga, la que se relaciona con los casos de empate, en que el voto del o de los representantes ausentes se sumará al del presidente o al del auxiliar.

a que se refieren los artículos 885 y 916 de esta Ley, el presidente de la Junta Federal de Conciliación y Arbitraje y los de las Juntas Especiales podrán ser sustituidos por auxiliares, pero intervendrán personalmente en la votación de las resoluciones siguientes: I. Competencia; II. Personalidad; III. Nulidad de actuaciones; IV. Sustitución de patrón; V. En los casos del artículo 772 de esta Ley; y VI. Cuando se trate de conflictos colectivos de naturaleza económica, en la que designe perito y en la que ordene la práctica de diligencias a que se refiere el artículo 913".

41 Moreno García, Fernando Javier, "Los principios procesales laborales", Laboral, México, Grupo Gasca, año X, núm. 109, octubre 2001, p. 30.

42 Disponible en http://mmw.stps.gob.mx/bp/secciones/junta_federal/secciones/consultas/reglamen to.html (consultada el 18 de diciembre de 2015). 
Sin embargo, no aplica la fracción III del artículo 620 relativa a la audiencia de discusión y votación del laudo, pues en el procedimiento de huelga no se dicta laudo alguno, ya que la imputabilidad o inimputabilidad es materia del procedimiento ordinario o del procedimiento para conflictos colectivos de naturaleza económica, como lo dispone el numeral 937, párrafo primero.

Respecto del artículo 928, en su fracción I, Juan B. Climént Beltrán expresa:

el presidente titular integrará la Junta Especial respectiva, conforme al artículo 620. En consecuencia, si se trata de un conflicto colectivo de naturaleza jurídica, como es el emplazamiento de huelga por violaciones al contrato, bastará la presencia del presidente titular o del auxiliar de la Junta Especial, para llevar adelante la audiencia de conciliación hasta su terminación. En cambio, si se trata de un emplazamiento de huelga por revisión de contrato colectivo, que supone en el fondo un conflicto colectivo de naturaleza económica, se requerirá, además de la presencia del presidente titular de la Junta, la de uno de los representantes, por lo menos. ${ }^{43}$

También debe tomarse en cuenta que el artículo 608 dispone que: "Cuando un conflicto afecte a dos o más ramas de la industria o de las actividades representadas en la Junta, ésta se integrará con el presidente de la misma y con sus respectivos representantes de los trabajadores y de los patrones". Por lo tanto, cuando el conflicto con el que se relacione el procedimiento de huelga involucre a dos o más ramas industriales o actividades representadas en la Junta, ${ }^{44}$ deberá intervenir el presidente titular y no los de las Juntas Especiales, conjuntamente con los respectivos representantes de los trabajadores y de los patrones.

\section{INTERVENCIÓN PERSONAL DEL PRESIDENTE}

En el procedimiento de huelga, el presidente titular de la Junta, sea que integre el Pleno o la Junta Especial competente, ${ }^{45}$ debe intervenir personal-

43 Climént Beltrán, Juan B., Elementos de derecho procesal del trabajo, 3a. ed., México, Esfinge, 2001, p. 276.

44 Sin que fueren todas ellas, pues en tal caso, el procedimiento de huelga sería competencia del Pleno de la JCA.

45 O las Juntas Especiales competentes, cuando el procedimiento de huelga se relacione con un conflicto que afecte a dos o más ramas de la industria o de las actividades representadas 
mente en las resoluciones siguientes, de conformidad con lo dispuesto en el artículo 928, fracción I:

a) Falta de personalidad;

b) Incompetencia;

c) Los casos de los artículos 469 (terminación de la huelga), 923 (denegación del trámite del escrito de emplazamiento de huelga) y 935 (determinación del número de trabajadores que deberán continuar laborando, en los casos en que pueda verse afectada la seguridad de la empresa, los bienes de producción o la reanudación de los trabajos); y

d) Declaración de inexistencia o ilicitud de huelga.

Como se puede advertir del contenido de los cuatro incisos anteriores, se trata de seis resoluciones de la mayor importancia en el procedimiento de huelga, ya que en tres de los casos (denegación del trámite del escrito de emplazamiento y declaración de inexistencia o ilicitud de huelga) puede concluir el procedimiento de huelga por causas atribuibles a los trabajadores; en la terminación de la huelga ésta finaliza por diferentes razones, y si la falta de personalidad aplica respecto de la coalición o sindicato emplazante, también concluye el procedimiento por motivos imputables a los trabajadores en tanto que la determinación del personal de seguridad se relaciona con la existencia misma del centro de trabajo, por lo cual se justifica que sea el presidente titular de la JCA quien intervenga y firme personalmente dichas resoluciones.

\section{NOTIFICACIONES Y TÉRMINOS PROCESALES}

Por disposición expresa del artículo 928, fracción II, en el procedimiento de huelga no serán aplicables las reglas generales respecto de términos para hacer notificaciones y citaciones; las notificaciones surtirán efectos desde el día y hora en que quedan hechas. Consecuentemente, los artículos contenidos en los capítulos VI (De los términos procesales: 733-738) y VII (De las notificaciones: 739-752), del título decimocuarto "Derecho procesal del trabajo",

en la JCA, sin que fueren todas las ramas y actividades, ya que tal caso sería competencia del Pleno. 
que resultan procedentes en todos los demás procedimientos laborales, previstos en la LFT, no se aplican en materia de huelga.

Néstor de Buen L., al analizar el cómputo de los términos, distingue la regla de carácter general en el derecho procesal del trabajo, frente a la norma particular correspondiente a los asuntos de huelga, como se indica a continuación:

En el artículo 736 se dispone lo siguiente: "Para computar los términos, los meses se regularán por el de treinta días naturales; y los días hábiles se considerarán de veinticuatro horas naturales, contados de las veinticuatro a las veinticuatro horas, salvo disposición contraria en esta ley". La fórmula, tan discutible como se quiera, intenta facilitar el cómputo de los meses y deja un cierto margen en el de los días, ya que debe entenderse que no empezarán a transcurrir sino a partir de las veinticuatro horas del día, salvo en los casos de huelga en que "Las notificaciones surtirán efectos desde el día y hora en que quedan hechas" (artículo 928-II). ${ }^{46}$

En virtud de que las normas previstas en el vigente artículo 928 no existieron en la LFT de 1931, sino que fueron incorporadas a la de 1970, en su numeral 458, antes de que iniciara su vigencia este segundo ordenamiento federal del trabajo, se promovieron juicios de amparo en los cuales los quejosos cuestionaron ante la Cuarta Sala de la SCJN — con motivo del ejercicio del derecho de huelga - el incumplimiento de las reglas generales aplicables en materia de notificaciones y términos procesales a los procedimientos laborales, como en el amparo en revisión en materia de trabajo 8238/46, promovido por María Ochoa, resuelto el 7 de mayo de 1947, por unanimidad de cuatro votos, cuya tesis refiere:

HuElgas, NOTIFICACIONES CON MOTIVO DE LAS. No es de tomarse en consideración lo alegado en el sentido de que la notificación a que se refiere la fracción II del artículo 265 de la Ley Federal del Trabajo, debe hacerse en la forma prescrita por el artículo 444 de la propia ley; porque las disposiciones contenidas en el título quinto de la Ley Federal del Trabajo, se refieren a conflictos de carácter colectivo que se sujetan a sus reglas especiales de procedimiento, y sólo a falta de disposición expresa en las citadas reglas,

46 Buen L., Néstor de, Derecho procesal del trabajo, México, Porrúa, 1988, p. 368. 
procede la aplicación de las disposiciones generales que se contienen en el título noveno del mismo ordenamiento, relacionadas con normas de procedimiento aplicables a los conflictos individuales, ya que si la mencionada fracción II del expresado artículo 265, exige que la copia del pliego de peticiones se haga llegar al patrón por la JCA, bajo su más estrecha responsabilidad, "el mismo día que la reciba", no se puede aceptar que la notificación se haga con las formalidades a que se refiere el artículo 444 de la Ley Federal del Trabajo, que indica que no encontrándose a la persona a quien debe notificarse ni a su encargado o representante, se le dejará citatorio para que espere a una hora determinada, del día siguiente, pues es indudable que esta norma procesal solamente es aplicable tratándose de conflictos individuales, y no en el procedimiento especial de huelga, para el cual existe la disposición terminante que se ha dejado señalada. ${ }^{47}$

Un criterio similar sustentó la misma Cuarta Sala de la SCJN, al resolver por mayoría de tres votos —el 11 de julio de 1949_ el amparo en revisión en materia de trabajo 8879/48, promovido por Empacadora de Productos Alimenticios La Fortaleza, S. A. de C. V., en los siguientes términos: "PREHUELGA, TÉRMINO DE LA. Los artículos 452, 453 y 454 informan el sistema de computación civil adoptado por la Ley Federal del Trabajo en materia de enjuiciamiento. No son aplicables para medir el término de la prehuelga, previsto en la fracción I, del artículo 265 de la citada ley laboral, que se cuenta de momento a momento, con inclusión de horas y días hábiles". 48

Análogamente, fue resuelto por la Cuarta Sala el 3 de enero de 1951, por unanimidad de cinco votos, el amparo en revisión en materia de trabajo 4808/50, del quejoso Ramírez Domingo de G., en el que se sostuvo lo siguiente:

HuElga, FORMA DEL EMPLAZAMIENTO EN LA. En el procedimiento especial que para las huelgas señalan los artículos 265 y siguientes de la Ley Federal del Trabajo; el primero de los conceptos citados, en su fracción II, establece: que presentado el pliego de peticiones ante la responsable, con copia para el presidente de la Junta, éste lo hará llegar al patrón, bajo su más estrecha responsabilidad, el mismo día que lo reciba. La entrega del pliego

47 Tesis aislada, Semanario Judicial de la Federación, Quinta Época, t. XCII, p. 1325.

48 Tesis aislada, Semanario Judicial de la Federación, Quinta Época, t. CI, p. 341. Nota: consideramos que la transcripción del texto de la tesis contiene un error, pues debe decir con inclusión de horas y días inhábiles, no hábiles. 
de peticiones y el emplazamiento no se rige en consecuencia por lo establecido en los artículos 442 y 444 de la Ley Federal del Trabajo para llevar a cabo las notificaciones y el emplazamiento en los juicios laborales, sino que queda al arbitrio del presidente de la Junta, la forma en que haga llegar al patrón el pliego petitorio, bajo su más estrecha responsabilidad. Por tanto, en el caso, el actuario no tenía por qué ceñirse a los indicados artículos 442 y 444 citados, sino que debía cumplir su cometido en la forma y términos en que se lo hubiera ordenado el presidente de la Junta, ya que la entrega del pliego petitorio era de la estrecha responsabilidad de éste, la que, en su caso, podía exigir el patrón emplazado, en los términos de los artículos 650 y siguientes de la Ley Federal del Trabajo. Lo anterior no quiere decir que si el patrón comprueba en el juicio de amparo que el pliego petitorio no ha llegado a su poder, es decir, que el presidente de la Junta no cumplió con lo que establece el artículo 265 de la Ley Federal del Trabajo y que a pesar de ello se sigue hasta el final el procedimiento de huelga, no esté en condiciones de obtener la protección federal, porque probada la inconstitucionalidad del acto reclamado, la violación de sus garantías individuales sería manifiesta, pero es indispensable que demuestre de modo fehaciente que no fue legalmente emplazado. ${ }^{49}$

Es evidente que, si bien no resultan aplicables las reglas generales en materia de notificaciones, cuando se ejercita el derecho de huelga por parte del sindicato o coalición emplazante de los trabajadores, también lo es que la notificación debe practicarse, ya que cuando ello no ocurre y ésta se omite, la violación de las garantías del empleador es incuestionable, como ocurrió en el amparo en revisión en materia de trabajo 2968/46, de la Panadería Cinco de Mayo, S. de R. L., resuelto por la Cuarta Sala de la SCJN, el 21 de agosto de 1947, por unanimidad de cinco votos, en que se consideró que al no haber hecho del conocimiento del patrón la fecha del recuento en un asunto de huelga, sino haberlo realizado inmediatamente después de que los huelguistas lo hubieran solicitado, y afirmado que estaban todos los trabajadores de la empresa sin que estuviera presente el empleador, obliga a conceder al quejoso el amparo reclamado. ${ }^{50}$

\footnotetext{
49 Tesis aislada, Semanario Judicial de la Federación, Quinta Época, t. CVII, p. 19.

50 Cfr. Huelgas, ReCuentos De trabajadores PARA LAS. Tesis aislada, Semanario Judicial de la Federación, Quinta Época, t. XCIII, p. 1739.
} 
Ya durante la vigencia de la LFT de 1970, se confirmó el criterio sustentado por la Cuarta Sala de la SCJN, por mayoría de razón, tomando en cuenta que dicho ordenamiento laboral incorporó las aún vigentes reglas en su artículo 458, que sirvió de fundamento al Tribunal Colegiado del Décimo Circuito para resolver —el 23 de septiembre de 1977 y por unanimidad de votos- el amparo en revisión 399/77, promovido por el Sindicato de Trabajadores de los Garajes, Gasolineras y Estaciones de Servicio del Estado de Yucatán, cuya tesis a la letra dice:

Huelga, PROCEDIMIENTO DE. PRECEPTO APLICABLE EN MATERIA DE NOTIFICACIONES. El título octavo en sus capítulos primero y segundo, de la nueva Ley Federal del Trabajo, regula los procedimientos de huelga y en la fracción II del artículo 458, comprendida en el capítulo segundo del referido título octavo, se establece que no serán aplicables las reglas generales respecto de los términos para hacer notificaciones y citaciones, y que las notificaciones surtirán sus efectos desde y el día y hora en que queden hechas. Por tanto, dicho precepto es aplicable en los procedimientos de huelga y no el artículo 693 de la ley laboral invocada, dado que este numeral contiene una norma genérica, y el 458, fracción II, la específica para el caso a que se alude, en atención a que el procedimiento de huelga debe ser sumario, para evitar en lo posible los perjuicios que ocasiona el paro de labores, razón que explica la existencia de la norma contenida en el último precepto citado. ${ }^{51}$

Una cierta resistencia, por parte de los tribunales del trabajo, se advierte en la aplicación del artículo 458, fracción III, ${ }^{52}$ de la LFT de 1970, que inició su vigencia el 1o. de mayo de dicho año, el cual — recogiendo los criterios de la Cuarta Sala de la SCJN_ ordenó que, en materia de huelga, todos los días y horas serían hábiles, como se desprende de la propuesta planteada por Baltasar Cavazos Flores, la que refiere:

Onceava deficiencia. Artículo 458, fracción III que previene que en los procedimientos de huelga "todos los días y horas serán hábiles". Ante la Junta Federal de Conciliación y Arbitraje se sigue el criterio de que los días feriados, festivos o de descanso, no se computan. Creemos más justo el

51 Tesis aislada, Semanario Judicial de la Federación, Séptima Época, vol. 103-108, sexta parte, p. 102.

52 Esta norma no existió en la LFT de 1931. 
criterio de la Junta que el de la Ley. Consecuencia: que se abrogue dicha fracción, para evitar problemas que generalmente afectan mucho más a los trabajadores. ${ }^{53}$

Respecto del mismo fenómeno de inobservancia legal se manifestó Juan B. Climént Beltrán, quien expuso:

sin ningún fundamento legal se estuvo siguiendo la práctica, durante muchos años, de no computar los días de vacaciones de la Junta para los términos de huelga. Más a partir de las reformas de 1980, se determinó claramente en la citada fracción III del artículo 928 la regla de que todos los días y horas serán hábiles; ordenándose medidas administrativas para la recepción de las promociones en cualquier tiempo. ${ }^{54}$

Es importante subrayar que — como lo señala el laboralista citado en el párrafo anterior - a partir de la reforma procesal de 1980 se regularizó la aplicación de la regla prevista en la LFT de 1970 (artículo 458, fracción III), que a partir del 1o. de mayo de 1980, correspondió a la fracción III del artículo 928, a la cual se agregó la oración “La Junta tendrá guardias permanentes para tal efecto"; y en la actualidad, la norma se observa con regularidad, aunque Raúl Chávez Castillo matiza dicha aplicación en su definición de las "Guardias permanentes para el caso de procedimiento de huelga", en los siguientes términos:

Personal que se encuentra en el local de la Junta en la sección de huelgas, para el efecto de que se realicen los actos urgentes inherentes al procedimiento de huelga. Sin embargo, esto resulta inexacto a virtud de que cuando el Tribunal del Trabajo se encuentra de vacaciones, realmente se encuentra cerrada el área de huelgas, y si bien es cierto se encuentra abierto el acceso al local de la Junta, sólo está a disposición del público o de las partes interesadas en el procedimiento de huelga, la secretaría general. (Artículo 928, fracción III) $)^{55}$

\footnotetext{
53 Cavazos Flores, Baltasar, "Deficiencias legislativas en materia de huelgas", Estudios de derecho procesal del trabajo en honor del doctor Alberto Trueba Urbina, México, Ediciones de la Universidad de Yucatán, 1977, p. 86.

54 Climént Beltrán, Juan B., Elementos de derecho..., cit., p. 278.

55 Chávez Castillo, Raúl, Diccionario de derecho del trabajo, 2a. ed., México, Porrúa, 2007, p. 77.
} 
Con independencia de que la atención de las promociones relativas al procedimiento de huelga se efectué en las secretarías auxiliares de "Emplazamientos a huelga" y de "Huelgas" o por conducto de la Secretaría General de la JFCA, de la definición anterior se desprende que sí se encuentra personal disponible para recibir y acordar las solicitudes de las partes, por lo que —en la práctica - se cumple la disposición que analizamos, prevista en el artículo 928, fracción III, de la LFT en vigor, sin que ello implique nuestra aceptación sobre la competencia de dicho personal, que pudiera no estar facultado para intervenir en el procedimiento en comento, por lo cual es necesario revisar los casos concretos, aunque si las actuaciones respectivas se firman por quien formalmente tenga las atribuciones legales, se observaría el debido proceso.

Aun cuando no existe fundamento legal sobre el tema, ya que se trata de una situación de hecho, ${ }^{56}$ como una medida preventiva, es importante tomar en cuenta la recomendación de Juan B. Climént Beltrán relacionada con el señalamiento de domicilio para recibir notificaciones en un lugar diferente al de la ubicación de la empresa o negociación, para el caso de que la huelga llegase a estallar, pues en tal supuesto, ya no podría recibir las notificaciones en ese lugar: "La empresa debe señalar un domicilio distinto al del centro de trabajo afectado por la huelga, para oír las notificaciones subsiguientes, pues, de no hacerlo, en caso de estallar la huelga, ya no podría ser notificada durante el conflicto en su propio centro de trabajo, y tendrían que hacerle las notificaciones por estrados". ${ }^{57}$

La fracción III del mismo numeral 928 dispone que todos los días y horas serán hábiles en el procedimiento de huelga, para lo cual, la Junta tendrá guardias permanentes; debe recordarse que — para el resto de los procedimientos laborales- los artículos 715 y 716 disponen que son días hábiles todos los del año con excepción de los sábados y domingos, los de descanso obligatorio, los festivos que señale el calendario oficial y aquéllos en que la Junta suspenda sus labores, y que son horas hábiles las comprendidas entre las siete y las diecinueve horas, salvo el procedimiento de huelga, en el que todos los

56 En la práctica, si llega a estallar la huelga, los trabajadores de hecho quedan a cargo del centro de labores, pues cierran los accesos al mismo y colocan banderas rojinegras en las entradas.

57 Climént Beltrán, Juan B., Formulario de derecho del trabajo, 3a. ed., México, Esfinge, 1974, p. 258. 
días y horas son hábiles, en virtud de lo cual, tanto las notificaciones como las audiencias y cualquier diligencia o actuación que se relacione con el procedimiento de huelga, pueden realizarse cualquier día y a cualquier hora.

Por cuanto al cómputo del periodo de pre huelga, ${ }^{58}$ resulta muy interesante citar las ideas de Nicolás Pizarro Suárez, autor de una de las obras jurídicas más antiguas sobre el tema — publicada en 1938 — quien después de señalar con base en ejecutorias de la SCJN, que "la huelga no es un procedimiento de las autoridades" y sí una "acción de los trabajadores en el sentido amplio de la palabra”, transcribe un fragmento de la resolución de fecha 30 de julio de 1937, dictada por la Junta Federal de Conciliación y Arbitraje, respecto de la huelga en contra de la Compañía de Petróleo "El Águila”, que resulta un precedente histórico de gran importancia, pues es el preludio de la expropiación petrolera que llevó a cabo el presidente Lázaro Cárdenas el 18 de marzo de 1938:

La empresa incurre en el error de aplicar los artículos 452, 453 y 454 que sólo se refieren a disposiciones procesales relacionadas con las funciones de las Juntas de Conciliación y Arbitraje, pues [...] salta a la vista [...] que tales disposiciones se refieren exclusivamente a reglas de procedimiento que deben seguir las autoridades al ejercer sus funciones, y que no pueden hacerse extensivas al término que conceden los obreros a los patrones en caso de emplazamiento de huelga, porque de haber sido ésta la voluntad del legislador, claramente la hubiera expresado en el artículo 265, fracción I [...] y de la simple lectura de ese precepto se descubre que el legislador sólo quiso que se concedieran seis días corridos, o diez, sin interrupción de ninguna naturaleza. Sin duda alguna la intención del legislador al establecer que se conceda tal término a los patrones para que estalle una huelga, fue la de que hubiera una posibilidad de avenimiento y que para el caso de que esto no sucediera, los patrones tengan conocimiento del día y hora exacta en que debe estallar una huelga y estén en posibilidad de tomar las medidas necesarias para evitar que se causen mayores perjuicios, y es evidente que al concederse el plazo de seis o diez días corridos para que estalle una huelga, se llena el fin que persiguió el legislador. ${ }^{59}$

58 Que inicia a partir del momento en que se entrega al empleador la copia del pliego de peticiones con emplazamiento a huelga, y termina el día y hora en que se suspenden las labores, conforme al señalamiento respectivo de la coalición o sindicato emplazante.

59 Pizarro Suárez, Nicolás, La buelga en el derecho mexicano, México, Ediciones Insignia, 1938, 
En la ponencia presentada por la JLCA del estado de Chiapas, titulada "Términos de notificaciones y citaciones en el procedimiento del incidente de declaratoria de inexistencia de la huelga", José Gonzalo Rashid Solís planteó como problema: "Es de considerarse debidamente notificadas a las partes en el conflicto, para concurrir a la audiencia de ofrecimiento y recepción de pruebas, en virtud de haber sido notificadas un día antes de la fecha de la misma, aun cuando manifiesten que es un plazo demasiado corto para ésta, y que la autoridad es responsable por no conceder un plazo mayor". ${ }^{60}$ Por lo cual, propuso como criterio de interpretación, el siguiente:

Si la Junta celebra la audiencia de ofrecimiento y recepción de pruebas, cuando ambas partes hayan sido notificadas un día antes de la celebración de dicha audiencia, debe estimarse que éstas se encuentran debidamente notificadas, ya que en el procedimiento respectivo las notificaciones surten efectos desde el día y hora en que quedan hechas, sin que sean aplicables las reglas generales respecto de términos para notificaciones y citaciones, pues debe considerarse que en el conflicto extraordinario de huelga, tomando en cuenta que se afecta el interés social, la tramitación del mismo debe ser desahogada con prontitud. ${ }^{61}$

Por su parte, Juan B. Climént Beltrán admite que — conforme al artículo 928, fracción II- no se requiere observar en las notificaciones para las audiencias y diligencias las reglas aplicables al procedimiento ordinario contenidas en el artículo 748, toda vez que podrán hacerse en cualquier hora del día y sin atenerse a la anticipación de veinticuatro horas del día y hora en que deba efectuarse la diligencia, como refiere, por ejemplo, respecto de la entrega del pliego de peticiones: "la notificación del emplazamiento a que se refiere el artículo 921 se entenderá efectuada al entregar el escrito del emplazamiento

pp. 138 y 139. Nota: las cursivas corresponden a la fuente consultada. Debe tomarse en cuenta que los comentarios del autor se relacionan con el ejercicio del derecho de huelga interpartes, es decir, con el periodo comprendido del 28 de agosto de 1931 al 10 de abril de 1941, en que los trabajadores entregaban directamente al patrón el pliego de peticiones y las pláticas conciliatorias se realizaban entre ambas partes, sin intervención de la JCA o de alguna otra autoridad del trabajo, y era hasta que se suspendían las labores con motivo de la huelga, cuando la JCA podía ejercer sus facultades para calificar el cumplimiento de los requisitos legales.

60 Secretaría del Trabajo y Previsión Social, Conclusiones. III Reunión de Juntas de Conciliación y Arbitraje, Morelia, Michoacán, 23-27 de julio de 1978, pp. 380 y 381.

61 Ibidem, p. 381. 
a cualquier persona que se encuentre en el lugar del domicilio del patrón, y surtirá efectos desde ese momento, sin requerirse el citatorio previo cuando no esté presente el interesado o su representante, a que se refiere la fracción III del artículo 743", pero sostiene que cuando se trata de la etapa de calificación de la huelga, las notificaciones deben hacerse "con la anticipación de veinticuatro horas por lo menos, a que se refiere el artículo 748, pues de otro modo se colocaría a las partes en estado de indefensión para ofrecer y preparar las pruebas que deseen rendir en la audiencia que señala el artículo 930”. ${ }^{62}$

En otra de sus obras, el mismo Climént Beltrán vincula su comentario anterior — relacionado con el artículo 928, fracción II- con el término para la presentación de la demanda de amparo:

Cabe hacer dos observaciones en relación con esta fracción: en primer lugar, de la misma se desprende una regla de excepción a lo dispuesto en el artículo 743 de la Ley Federal del Trabajo, en el sentido de que la notificación se practicará con la persona que se encuentre en la casa o local señalado como domicilio del patrón a quien se va a emplazar, y surtirá sus efectos desde ese momento, sin que se requiera dejar citatorio para que lo esperen al día siguiente, en el caso de que no esté presente el interesado o su representante.

Además, la reforma al artículo 21 de la Ley de Amparo, contenida en el decreto publicado en el DOF de 16 de enero de 1984, establece que el término para la interposición de la demanda de amparo será de quince días, el cual "se contará desde el día siguiente al en que haya surtido efectos, conforme a la Ley del acto la notificación al quejoso de la resolución o acuerdo que reclame". En consecuencia, esta reforma incide en el término para la interposición del amparo en materia de huelga, en cuanto a que se computará a partir del momento en que se haya efectuado la notificación del acto reclamado en el procedimiento de huelga, conforme al artículo 928, fracción II, de la Ley Federal del Trabajo. ${ }^{63}$

Respecto del cálculo del término de veinticuatro horas para que los trabajadores reanuden sus labores, ${ }^{64}$ cuando la JCA declara la inexistencia legal

\footnotetext{
62 Climént Beltrán, Juan B., Ley Federal..., cit., p. 605.

63 Climént Beltrán, Juan B., Elementos de derecho..., cit., p. 276.

64 Artículo 932. Si la Junta declara la inexistencia legal del estado de huelga: I. Fijará a los trabajadores un término de veinticuatro horas para que regresen a su trabajo.
} 
del estado de huelga, la Segunda Sala de la SCJN estableció por unanimidad de votos la tesis de jurisprudencia 2a./J. 38/2011 (10a.), con fecha veintitrés de noviembre de dos mil once, relacionada con la contradicción de tesis $405 / 2011$, entre las sustentadas por los tribunales colegiados segundo y quinto, ambos del décimo quinto circuito, para esclarecer que dicho término corre desde que se efectúa la notificación de la resolución que lo ordena, aun cuando, conforme a las condiciones de prestación del servicio, se trate de un día u hora inhábil para el centro de trabajo, para los trabajadores o para ambos, ya que ello sólo trae como resultado la obligación de que los trabajadores asistan a reanudar su trabajo en el primer momento hábil que conforme a sus condiciones laborales les corresponda, como se expresa en la tesis a la que se alude, cuyo rubro y texto, refiere:

INEXISTENCIA LEGAL DEL ESTADO DE HUELGA. CÓMPUTO DEL TÉRMINO DE 24 HORAS PARA QUE LOS TRABAJADORES REANUDEN SUS LABORES. De la evolución del derecho de huelga se advierte que el legislador ha procurado la celeridad del procedimiento respectivo para evitar, en lo posible, una afectación indebida a las partes en conflicto; en ese contexto, las fracciones I y II del artículo 932 de la Ley Federal del Trabajo disponen que si la Junta declara la inexistencia legal del estado de huelga, fijará a los trabajadores un término de 24 horas para que regresen a su trabajo, notificando esto por conducto de la representación sindical y apercibiendo a los trabajadores que por el solo hecho de no acatar la resolución quedarán terminadas las relaciones de trabajo, salvo causa justificada. Ahora bien, acorde con el artículo 716 de la indicada Ley, en materia de huelga todos los días y horas son hábiles, lo que se reitera en el numeral 928 que, en sus fracciones II y III, establece que en el procedimiento de huelga no serán aplicables las reglas generales respecto de términos para hacer notificaciones y citaciones, que las notificaciones surtirán efectos desde el día y hora en que quedan hechas, así que todos los días y horas serán hábiles, para lo cual la Junta tendrá guardias permanentes. Atento a la finalidad de la norma, se concluye que el término de 24 horas citado corre desde que se efectúa la notificación de la resolución que lo ordena, no obstante que, conforme a las condiciones de prestación del servicio, se trate de un día u hora inhábil para la fuente de trabajo, para los trabajadores o para ambos, pues ello sólo trae como consecuencia la ineludible obligación de que los trabajadores se presenten a reanudar su trabajo en el primer momento hábil que conforme a sus condi- 
ciones laborales les corresponda, pues en ese supuesto, el plazo de 24 horas para hacerlo ya transcurrió. ${ }^{65}$

No obstante que el comentario jurídico de Francisco Breña Garduño se relaciona con el procedimiento de imputabilidad de la huelga, el cual — como señalamos con anterioridad - no forma parte del procedimiento de huelga previsto en el capítulo XX (artículos 920 a 938) que analizamos, pues para la instrucción de aquél debe seguirse el trámite del juicio ordinario o el que corresponde a los asuntos de orden económico, según resulte, en función del conflicto colectivo con el que se relacione la huelga, esto es, de naturaleza jurídica o de carácter económico, es conveniente mencionarlo, dada la estrecha vinculación que existe procesalmente entre los procedimientos citados, como se puede advertir a continuación:

Si a pesar de que el patrón oportunamente designó el lugar donde deben practicársele notificaciones personales, éstas no se practican en dicho lugar, y suponiendo que el emplazamiento al patrón en el procedimiento de imputabilidad de la huelga se hiciera en un lugar diverso, dicho patrón, si no ha concurrido para nada al procedimiento y éste se ha tramitado, dictándose incluso laudo condenatorio en su contra, declarando imputable a él los motivos de la huelga con todas sus consecuencias, puede impugnar en juicio de amparo indirecto ese procedimiento irregular por violación de la garantía de audiencia, ya que no ha sido oído y vencido en juicio siguiendo el procedimiento establecido; en ese supuesto se considera como persona extraña al procedimiento, y como tal no está obligado previamente a la promoción del juicio de amparo a interponer o agotar los medios ordinarios de defensa por no haberse practicado las notificaciones en la forma prevista por la Ley. ${ }^{66}$

Para concluir este apartado, es conveniente reiterar que la fracción III del artículo 928 única y exclusivamente aplica en materia de huelga, no así en otros rubros de la legislación laboral, como inexactamente lo considera Francisco Córdova Romero, quien señala: "El patrón emplazado para dar contestación al pliego petitorio con efectos a emplazamientos a huelga, deberá

65 Tesis 2a./J. 38/2011 (10a.), Semanario Judicial de la Federación y su Gaceta, Décima Época, t. 2, febrero de 2012, p. 1163.

66 Citado por Cavazos Flores, Baltasar, El mito del arbitraje potestativo, México, Jus, 1978, pp. 91 y 92. 
tomar en cuenta que la notificación surte efectos desde la hora y fecha en que se haga, y que en los términos se incluyen sábados, domingos y días festivos, por ser días hábiles tratándose de derecho colectivo". ${ }^{67}$

El error en que incurre el autor citado proviene de considerar incluidos en los términos los sábados, domingos y días festivos, puesto que ello ocurre exclusivamente en el procedimiento de huelga, como expresamente lo dispone el citado artículo 928, fracción III, no así en el resto de las instituciones laborales del derecho colectivo, en que no existe fundamento legal aplicable, como serían por ejemplo el registro de un sindicato o el depósito de un contrato colectivo de trabajo ante la autoridad competente.

\section{NO DENUNCIABILIDAD DE LOS MIEMBROS DE LA JUNTA DE CONCILIACIÓN Y ARBITRAJE}

Dos temas regula la fracción IV del artículo 928, los cuales son, la no denunciabilidad de los miembros de la Junta y el trámite del incidente de falta de personalidad; en cuanto al primero, ordena categóricamente la inaplicación del numeral 710 relativo a la existencia de impedimentos legales para conocer de algún juicio, por parte del representante del Gobierno, de los patrones o de los trabajadores ante la JCA o el auxiliar que se encuentre interviniendo, quienes no se hubieren excusado a pesar de estar impedidos o que el interesado considere que lo están, para intervenir en el procedimiento de huelga, en cuyo caso, las partes no están facultadas para promover la correspondiente denuncia, ante la prohibición expresa del legislador.

Si efectuamos una interpretación literal de la parte relativa a la no denunciabilidad de los integrantes de la JCA, prevista en el artículo 928, fracción IV, que dispone: "No serán denunciables en los términos del artículo 710 de esta Ley, los miembros de la Junta" podemos llegar a la conclusión de que esta norma es innecesaria pues el precepto al que remite, alude a impedimentos "para conocer de algún juicio" y al través del procedimiento de huelga no se tramita juicio alguno, sin embargo, debemos entender que lo que el legislador quiso indicar fue que, de manera contraria a los impedimentos en los juicios labo-

67 Córdova Romero, Francisco, Derecho procesal del trabajo, 4a. ed., México, Cárdenas Velasco Editores, 2006, p. 148. 
rales, en el procedimiento de huelga resulta inaplicable la denuncia respectiva; en nuestra opinión, es innecesario que el artículo 928, fracción IV, remita al diverso numeral 710, y sería más sencillo que sólo dispusiera que: "No serán denunciables los miembros de la Junta”, tal y como lo hizo la LFT de 1970, como lo veremos más adelante.

Sobre el tema en comento, localizamos el antecedente que cita Nicolás Pizarro Suárez al analizar el "Procedimiento en el incidente de calificación de la huelga”, durante la vigencia de nuestra primera LFT (1931), en la etapa del ejercicio del derecho de huelga inter partes:

Decimos, pues, que en el procedimiento de que hablamos deben cumplirse las formalidades esenciales del mismo, pero no todas las disposiciones procesales de la Ley que pudieran pensarse aplicables, como las relativas a las formalidades previas al laudo, o un caso que se ha presentado con cierta frecuencia: la cuestión de si son o no recusables los representantes del capital o del trabajo ante las Juntas cuando éstos pertenezcan a alguna agrupación antagónica (artículo 448). El Departamento del Trabajo, ${ }^{68}$ en consulta de 27 de septiembre de 1937 (R. M. T. IX-280), ${ }^{69}$ resolvió esta cuestión en sentido negativo, de acuerdo con la jurisprudencia constante sobre el particular de la Junta Federal, la cual está fundada en que "existe un interés social en que tales conflictos sean resueltos a la mayor brevedad". ${ }^{70}$

Opuesta al criterio anterior, y ya durante la etapa del ejercicio triangular del derecho de buelga, se manifestó la Confederación Proletaria Nacional, por conducto de Manuel Rivera, Manuel Huerta y Enrique Rangel, quienes en el documento de fecha 1o. de julio de 1949, que presentaron en el Congreso Mexicano del Derecho del Trabajo y Previsión Social, propusieron reformar varios preceptos de la LFT de 1931 —entre ellos el relativo al tema que analizamos - para lograr que el trámite de los asuntos que llegan a los tribunales de trabajo fuera rápido y con mayores garantías para las partes:

68 La Secretaría del Trabajo y Previsión Social fue creada por el presidente Manuel Ávila Camacho, quien promulgó en 1940 una nueva Ley de Secretarías de Estado, para convertir al Departamento del Trabajo en la Secretaría del ramo laboral.

69 Las siglas corresponden a la Revista Mexicana del Trabajo.

70 Pizarro Suárez, Nicolás, op. cit., p. 178. 


\section{[...]}

ART. 491. DiCE ACTUALMENTE: "La recusación se propondrá al concluir la audiencia de demanda y excepciones, cuando la causa en que se funde sea anterior al pleito y se tenga conocimiento de ella. Cuando sea posterior a la audiencia de demanda y excepciones el conocimiento de la causa de recusación o la causa misma, la deberá proponer la parte interesada tan luego llegue a su noticia. No justificándose este extremo, será desechada la recusación".

Aun cuando gramaticalmente la regla tiene toda amplitud, la interpretación que a este artículo le han dado los tribunales del trabajo y la Suprema Corte es en extremo limitativa, a tal grado que, en materia de huelgas y conflictos económicos que son precisamente los casos en que se versan más trascendentales intereses de las partes, no se permite la recusación, so pretexto de que hay interés en tramitar rápidamente el asunto. En tal virtud proponemos que la redacción de este artículo se reforme en los siguientes términos:

"La recusación se propondrá al presentar ante la Junta de Conciliación y Arbitraje correspondiente la demanda inicial, el pliego de peticiones con emplazamiento de huelga, o la solicitud inicial en un conflicto de orden económico, según se trate de uno u otro caso; o bien al recibir la notificación de tales documentos oficialmente por medio de la Junta. Las autoridades a quienes toca conocer de estas recusaciones tramitarán inmediatamente el incidente respectivo precisamente dentro de los plazos señalados por la Ley, en los casos de huelga, mientras se resuelve sobre la recusación podrá seguir conociendo el recusado si fuere preciso, pero sin llegar a conocer por ningún concepto de su resolución salvo el caso de que la recusación resultare desechada. Cuando sea posterior al momento indicado, el conocimiento de la causa de la recusación o de la causa misma, dicha recusación la planteará el interesado tan pronto tal causa llegue a su noticia. En los casos de recusación por causa de antagonismo gremial, bastará que el presidente de la Junta tenga conocimiento de que dicho antagonismo existe de hecho, para que sea procedente la recusación". ${ }^{71}$

La propuesta de la Confederación Proletaria Nacional para admitir la recusación de los miembros de la JCA en el ejercicio del derecho de huelga dentro

71 Secretaría del Trabajo y Previsión Social, Memoria del Congreso Mexicano de Derecho del Trabajo y Previsión Social (19 al 23 de julio de 1949), México, Talleres Gráficos de la Nación, 1950, t. II, pp. 27 y 28. 
de la normativa prevista en la LFT de 1931, fue rechazada y, por el contrario, la LFT de 1970 la prohibió expresamente, en el artículo 458, fracción IV, que disponía: "No serán recusables los miembros de la Junta" en materia de huelga; a su vez, la reforma procesal de 1980 sólo sustituyó el adjetivo "recusables", que significa que se pueden recusar, por el distinto adjetivo "denunciables", que quiere decir que se pueden denunciar, y agregó la remisión: “en los términos del artículo 710 de esta Ley" texto que se incorporó en el artículo 928, fracción IV, el que la reforma laboral de 2012 no modificó.

$\mathrm{Al}$ respecto, conviene citar a Juan B. Climént Beltrán, quien — sobre los impedimentos y excusas en la reforma procesal de 1980 — nos explica que:

Las excusas sustituyen a las recusaciones de la Ley anterior (artículo 707). Especialmente tiene interés la contenida en la fracción IV de dicho precepto, relativo a las denuncias de los litigantes o abogados en contra de los miembros de la Junta, que ahora sólo operan cuando se ejerce la acción penal, con lo que han quedado descartadas como subterfugio para entorpecer el proceso, pues el ejercicio de la acción penal es privativo del Ministerio Público.

Cabe distinguir entre las excusas solicitadas por el funcionario impedido, que se calificarán de plano, tramitándose según lo dispuesto en el artículo 709 de la Ley Federal del Trabajo, y las excusas por denuncia del impedimento por alguna de las partes, en cuyo caso se requerirá una audiencia en donde se oiga a los interesados y se reciban las pruebas de los mismos, de conformidad con el artículo 710. En ambos casos será necesaria la promoción por escrito; con la modalidad de que en ningún caso se suspenderá el procedimiento mientras se tramita la excusa, salvo disposición en contrario de la Ley, según dispone el artículo 712.

Hay que hacer notar que, conforme a lo dispuesto en el artículo 928 fracción IV, "no serán denunciables en los términos del artículo 710 de esta Ley, los miembros de la Junta", cuyo precepto atañe al procedimiento de huelga. ${ }^{72}$

El mismo autor citado con anterioridad, en relación con la fracción IV del artículo 928 de la reforma procesal de 1980, que no fue modificada por la reforma laboral 2012, refiere particularmente:

72 Climént Beltrán, Juan B., Elementos de derecho..., cit., pp. 135 y 136. 
La Ley de 1970 se refería a la improcedencia de la recusación, y como ésta ha sido suprimida a partir de las reformas de 1980, se indica que no serán denunciables los miembros de la Junta, lo que es explicable porque la celeridad del procedimiento de huelga sería incompatible con el trámite de un incidente para sustituir por impedimento a alguno de los miembros de la Junta. No obstante, creemos que será procedente la excusa de cualquiera de los miembros de tribunal, cuando considere que está impedido para integrar la Junta, por alguno de los impedimentos que señala el artículo 707 de la Ley Laboral; en la inteligencia de que esa excusa deberá resolverse de plano, sin abrir incidente, y sin suspensión del procedimiento, conforme a lo dispuesto en el artículo 711, en relación con el 928 fracción $I V .{ }^{73}$

Resulta muy interesante la interpretación que realiza Juan B. Climént Beltrán pues —en efecto — la parte relativa del texto correspondiente a la fracción que analizamos, expresa y claramente dispone: "No serán denunciables en los términos del artículo 710 de esta Ley, los miembros de la Junta", en virtud de lo cual, la exégesis que lleva a cabo el laboralista mencionado es correcta —en nuestra opinión_-, lo cual significa que ninguna de las partes en el juicio correspondiente, cuando tenga conocimiento que el representante del Gobierno, de los patrones o los trabajadores ante la Junta o el auxiliar, se encuentran impedidos para conocer de algún juicio y no se abstengan de hacerlo, puede presentar la denuncia respectiva, pero ello no impide que los sujetos mencionados motu proprio (de propia voluntad) ${ }^{74}$ puedan excusarse de los juicios en que intervengan.

Sin embargo, como hicimos notar con anterioridad, el procedimiento de huelga no constituye juicio alguno, ya que sólo tiene por objeto garantizar la suspensión de labores cuando se han cumplido las formalidades previstas por la propia ley, sin que exista un pronunciamiento respecto al fondo del conflicto, y su finalidad es tutelar jurídicamente el paro de actividades porque se han observado los requisitos de fondo y forma previstos por la ley, por lo cual no se surtiría la hipótesis del artículo 710, que se refiere a los impedimentos para conocer de "algún juicio", no obstante, debe reconocerse que —en el procedimiento de huelga — se presenta una situación análoga, pues

\footnotetext{
73 Ibidem, p. 278.

74 Corresponderían a las "excusas solicitadas" y no a las "excusas por denuncia", como las denomina Juan B. Climént Beltrán.
} 
se pueden dictar varias resoluciones ${ }^{75} \mathrm{y}$, por ello, la existencia de alguno de los impedimentos previstos en el artículo 707, pudiera presumir parcialidad en el sentido del voto que se emitiera.

Por lo tanto, si el miembro de la JCA que considera tener alguno de los impedimentos legales, prefiere dejar de intervenir en el procedimiento de huelga, a fin de que no se cuestione su imparcialidad, puede plantear su excusa (que se trataría de una excusa solicitada y no por denuncia, como las identifica Climént Beltrán), la cual deberá acreditar mediante los medios de prueba admisibles en materia laboral, y calificarse de plano por los sujetos a que se refiere el artículo 709, fracción I, incisos a) y b).

Consecuentemente, estamos de acuerdo con el laboralista citado, en cuanto que, si bien es cierto que los miembros de la JCA o el auxiliar que se encuentre interviniendo, no pueden ser denunciados por el patrón o los trabajadores en el procedimiento de huelga, si tienen algún impedimento, ellos pueden — voluntariamente- excusarse de participar en el mismo, haciendo valer la excusa respectiva, la cual deberá resolverse de plano, sin abrir incidente, y sin suspender el procedimiento, toda vez que si el legislador hubiera querido excluir la presentación de excusas en el caso que nos ocupa, debió haberlo referido expresamente, por ejemplo: "No serán denunciables ni se podrán excusar los miembros de la Junta”.

Finalmente, un tópico que también se relaciona con la interpretación de la fracción IV del artículo 928, consiste en el uso del nombre masculino y femenino "miembro" que significa "individuo que forma parte de un conjunto, comunidad o corporación", ${ }^{76}$ pues pudiera pensarse que tal referencia aplica únicamente respecto de los representantes del Gobierno, del capital y

75 Que aunque no se relacionan con el fondo del conflicto vinculado con la huelga, sí poseen gran importancia en el procedimiento, como son: 1) Denegación del trámite al escrito de emplazamiento de huelga que se atribuye legalmente al presidente de la Junta (artículo 923), pero, en la práctica, la suscriben los tres integrantes de la misma; 2) Resolución del incidente de falta de personalidad que hubieran promovido el patrón o los trabajadores (artículo 928, fracción IV); 3) Declaración de incompetencia (artículo 928, fracción V); 4) Declaración de inexistencia de la huelga (artículo 932); 5) Calificación de ilicitud de la huelga (artículo 934); y 6) Fijación del número indispensable de trabajadores que deberá continuar trabajando, para que sigan ejecutándose las labores cuya suspensión perjudique gravemente la seguridad y conservación de los locales, maquinaria y materias primas o la reanudación de los trabajos (artículo 935).

76 Diccionario de la lengua española, Real Academia Española; disponible en http://dle.rae. es/ ?id=PDfN5jE (consulta de 8 de enero de 2016). 
del trabajo que forman la Junta, en términos de lo dispuesto en el artículo 123, apartado A, fracción XX, de la CPEUM, ${ }^{77}$ sin embargo, debe tomarse en cuenta que la LFT, para aludir a estos representantes, utiliza el concepto de "integración” (artículos 605, párrafo primero; 607, párrafo primero; 608 y 609), por lo cual, si el legislador hubiera querido limitar la no denunciabilidad sólo de estos sujetos en el procedimiento de huelga, hubiera utilizado tal nombre y disponer: "No serán denunciables los integrantes de la Junta", en virtud de lo cual, debe considerarse — en el caso que analizamos - un uso extensivo del vocablo "miembros" para incluir no sólo a los tres representantes integrantes de la JCA, sino también al auxiliar que puede sustituir al presidente de la misma.

77 "XX. Las diferencias o conflictos entre el capital y el trabajo se sujetarán a la decisión de una Junta de Conciliación y Arbitraje, formada por igual número de representantes de los obreros y de los patronos, y uno del Gobierno". 